\title{
JCZS: An Intermolecular Potential Database for Performing Accurate Detonation and Expansion Calculations
}

\author{
Michael L. Hobbs, Melvin R. Baer, and Bruce C. McGee* \\ Engineering Sciences Center, Sandia National Laboratories, Albuquerque, NM
} \author{
87185
}

Prestis

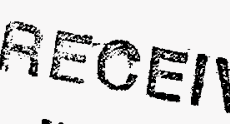

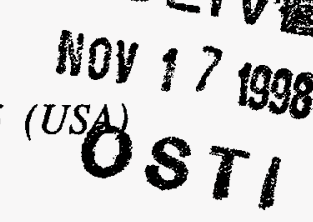

\begin{abstract}
Exponential-13,6 (EXP-13,6) potential parameters for 750 gases composed of 48 elements were determined and assembled in a database, referred to as the JCZS database, for use with the Jacobs Cowperthwaite Zwisler equation of state (JCZ3-EOS). ${ }^{(1)}$ The EXP-13,6 force constants were obtained by using literature values of Lennard-Jones (LJ) potential functions, by using corresponding states (CS) theory, by matching pure liquid shock Hugoniot data, and by using molecular volume to determine the approach radii with the well depth estimated from high-pressure isentropes. The JCZS database was used to accurately predict detonation velocity, pressure, and temperature for $\mathbf{5 0}$ different explosives with initial densities ranging from $0.25 \mathrm{~g} / \mathrm{cm}^{3}$ to $1.97 \mathrm{~g} / \mathrm{cm}^{3}$. Accurate predictions were also obtained for pure liquid shock Hugoniots, static properties of nitrogen, and gas detonations at high initial pressures.
\end{abstract}

\section{INTRODUCTION}

Thermochemical equilibrium codes, such as TIGER ${ }^{(2)}, \mathrm{CHEETAH}^{(3)}, \mathrm{PANDA}^{(4)}$, or $\mathrm{CHEQ}^{(5)}$, have been used with Chapman-Jouguet (CJ) detonation theory ${ }^{(6)}$ to determine the detonation state and expansion conditions along the $\mathrm{CJ}$ adiabat to characterize various energetic materials. Such calculations require the identity of product species as well as an accurate description of the P-V-T relationship or EOS of these product species. Most of the extensively used EOS relationships, such as the semi-empirical Becker-Kistiakowski-Wilson (BKW) EOS, are complex empirical fits to limited detonation velocity measurements. The BKW-EOS does not give adequate predictions for intermediate and low-pressure conditions, such as detonation of gases at elevated initial pressures, detonation of lowdensity condensed explosives, detonation of nonideal explosives, or expansion of detonation products along the CJ adiabat. Other more complex intermolecular potential-based EOS models, such as implemented in PANDA ${ }^{(4)}$ or $\mathrm{CHEQ}^{(5)}$, do perform better in expansion states, but do not consider an adequate number of product species. The hypothesis addressed in the present paper is that improved predictions of explosive performance can be realized by using an intermolecular potential-based EOS with a sufficient number of product species.

* This work performed at Sandia National Laboratories. Sandia is a multiprogram laboratory operated by Sandia Corporation, a Lockheed Martin Company, for the U.S. Department of Energy under contract DEAC04-94AL85000 
In 1976, Cowperthwaite and Zwisler ${ }^{(1)}$ presented the JCZ3-EOS and concluded that "additional work on JCZ3 should include a parameter study to determine the best set of values of the potential constants and the evaluation of potential constants for species not considered in the [1976] calculations." Baker and Stiel ${ }^{(7)}$ have attempted to optimize the JCZ3 parameters for 10 gas species $\left(\mathrm{CO}_{2}, \mathrm{H}_{2} \mathrm{O}, \mathrm{N}_{2}, \mathrm{O}_{2}, \mathrm{H}_{2}, \mathrm{NO}, \mathrm{NH}_{3}, \mathrm{CH}_{4}, \mathrm{CO}\right.$, and $\left.\mathrm{CHO}_{2} \mathrm{H}\right)$ with marginal success but did not try to find JCZ3 parameters for additional species. In the present paper, EXP-13,6 potentials were characterized for 750 gases for use with the JCZ3-EOS to give a substantial improvement in predictive capability.

The JCZ3-EOS uses an equation based on P-V-T relationships similar to the Mie-Grüneisen $\mathrm{EOS}^{(8)}$ :

$$
P=\frac{G(V, T, \varphi) n R T}{V}+P_{0}(V, \varphi)
$$

where $P, n, R, T$, and $V$ represent the pressure, number of moles, universal gas constant, and volume, respectively. The form of the Grüneisen function, $G$, and the volume dependent internal pressure function, $P_{0}$, is documented by Cowperthwaite and Zwisler. ${ }^{(1)}$ Both $G$ and $P_{o}$ depend on of the exponential 6 potential function $(E X P-\eta, 6), \varphi$ :

$$
\varphi(r)=\varepsilon[\underbrace{\left.\frac{6}{\eta-6}\right) \exp \left[\eta\left(1-r / r^{*}\right)\right]}_{\text {repulsive term }}-\underbrace{\left.\left(\frac{\eta}{\eta-6}\right)\left(\frac{r^{*}}{r}\right)^{6}\right]}_{\text {attractive term }},
$$

where $\varepsilon$ is the well depth for the pair potential and $r *$ is the radius of the minimum pair potential energy. The potential function is composed of a repulsive term that dominates at small values of $r$ and an attractive term that dominates at large values of $r$. The molecular force parameters $\varepsilon, \eta$, and $r^{*}$ are required for each product species. The force constant, $\varepsilon$, is often given as $\varepsilon / k$, where $k$ is Boltzmann's constant. The explicit dependence of the Grüneisen function, $G$, and the volume-dependent internal pressure function, $P_{0}$, on the potential function, $\varphi$, is not obvious, and the interested reader is referred to Ref. 1 for more information.

The sensitivity of the potential function to $\eta$ and $\varepsilon / k$ is shown in Fig. 1. The EXP- $\eta, 6$ potential is least sensitive to changes in $\eta$ and most sensitive to changes in $r^{*}$ and $\varepsilon / k$. In the present study, $\eta$ is assumed to be 13 for all molecules, leaving $r^{*}$ and $\varepsilon / k$ to be determined for each molecule. Hobbs and Baer ${ }^{(9)}$ have shown that the investigators using $\eta=13$ give the best agreement between measured and predicted pure liquid shock Hugoniots than other values of $\eta$. The EXP-13,6 is also a good representation of the Lennard Jones (LJ) potential function, $\varphi(r)=4 \varepsilon\left[(\sigma / r)^{12}-(\sigma / r)^{6}\right]$, as shown in Fig. 1.

\section{Lennard Jones Potential Parameters}

The force constants for the EXP-13,6 potential function are directly related to the LJ force constants. As shown in Fig. 1, the potential well depth, $\varepsilon / k$, is the same for both the LJ and EXP-13,6 potential function. The EXP13,6 characteristic radius, $r^{*}$, can be obtained from the LJ characteristic radius, $\sigma$, as follows: ${ }^{(10,11)} r^{*}=\sigma \times 2^{1 / 6}$. 


\section{DISCLAIMER}

This report was prepared as an account of work sponsored by an agency of the United States Government. Neither the United States Government nor any agency thereof, nor any of their employees, make any warranty, express or implied, or assumes any legal liability or responsibility for the accuracy, completeness, or usefulness of any information, apparatus, product, or process disclosed, or represents that its use would not infringe privately owned rights. Reference herein to any specific commercial product, process, or service by trade name, trademark, manufacturer, or otherwise does not necessarily constitute or imply its endorsement, recommendation, or favoring by the United States Government or any agency thereof. The views and opinions of authors expressed herein do not necessarily state or reflect those of the United States Government or any agency thereof. 


\section{DISCLAIMER}

Portions of this document may be illegible in electronic image products. Images are produced from the best available original document. 
submitted to Propellants, Explosives, Pyrotechnics

About 200 of the 750 species listed in the JANNAF tables ${ }^{(7)}$ have LJ parameters. McGee et al. ${ }^{(10)}$ give the references for the $\mathrm{LJ}$ parameters used in the present study.

\section{Corresponding States Estimates}

The corresponding states assumption, as originally proposed by van der Waals ${ }^{(12)}$, is that the behavior of all substances are similar at the same reduced temperature $\left(T / T_{c}\right)$, pressure $\left(P / P_{c}\right)$, and volume $\left(V / N_{c}\right)$. Pitzer ${ }^{(13)}$ derived van der Waals' corresponding states principle by assuming 1) classical statistics, 2) spherically symmetric nonpolar molecules, 3) similar molecular vibrations for both liquid and gaseous states, and 4) conformal molecules. The conformal assumption implies that the functionality of the intermolecular potential is the same, although the force constants vary from molecule-to-molecule. Ross and $\operatorname{Re}^{(14)}$ used the corresponding states assumption as originally proposed by Hirschfelder et al. ${ }^{(11)}$ to determine force constants for simple molecules as follows:

$$
r^{*}=r_{\mathrm{ar}}^{*}\left(V_{\mathrm{c}} / V_{c, a r}\right)^{1 / 3} ; \varepsilon / k=\varepsilon_{\mathrm{ar}} / k\left(T_{c} / T_{c, a r}\right)
$$

where $V_{c}$ and $T_{c}$ are critical volume and critical temperature, respectively. The subscript ar refers to argon as the corresponding molecule. The values of $r^{*}{ }_{\mathrm{ar}} \varepsilon_{\mathrm{ar}} / k, V_{c, a r}$ and $T_{c, a r}$ used in the present study are $3.85 \AA$ and $122 \mathrm{~K}, 74.9$ $\mathrm{cm}^{3} / \mathrm{mol}$, and $150.8 \mathrm{~K}$, respectively.

Wilding and Rowley ${ }^{(15)}$ obtained better predictions of thermophysical properties for nonspherical and polar molecules by performing Taylor series expansions about simple fluids with respect to geometry and polarity. Hobbs and $B a e r^{(9)}$ used these techniques with some success to determine EXP-13,6 force parameters for nonspherical and/or polar molecules with the following equations:

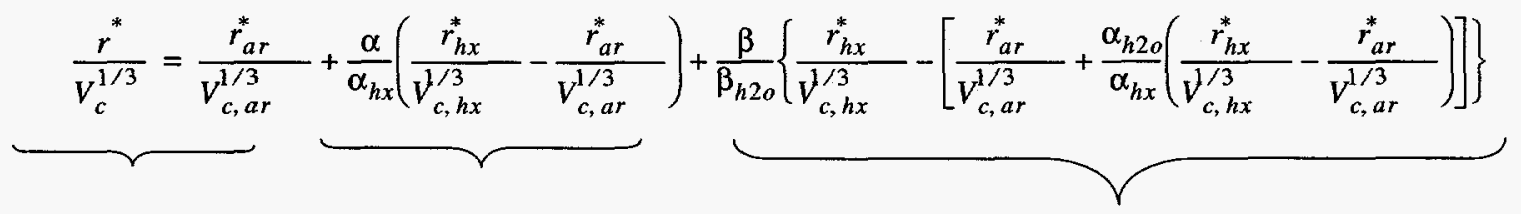

$$
\begin{aligned}
& \begin{array}{l}
\text { Correspond- Shape Corrections } \quad \text { Polar Corrections } \\
\text { ing States }
\end{array} \\
& \overbrace{}^{\sim} \overbrace{0} \\
& \frac{\varepsilon / k}{T_{c}}=\frac{\varepsilon_{a r} / k}{T_{c, a r}}+\frac{\alpha}{\alpha_{h x}}\left(\frac{\varepsilon_{h x} / k}{T_{c, h x}}-\frac{\varepsilon_{a r} / k}{T_{c, a r}}\right)+\frac{\beta}{\beta_{h 2 o}}\left\{\frac{\varepsilon_{h x} / k}{T_{c, h x}}-\left[\frac{\varepsilon_{a r} / k}{T_{c, a r}}+\frac{\alpha_{h 2 o}}{\alpha_{h x}}\left(\frac{\varepsilon_{h x} / k}{T_{c, h x}}-\frac{\varepsilon_{a r} / k}{T_{c, a r}}\right)\right]\right\} .
\end{aligned}
$$

The first terms marked "Corresponding States" in Eqs. (4) and (5) represent the simple-corresponding states law given in Eq. (3). The last two terms on the right-hand side of Eqs. (4) and (5) represent geometrical deviations and polar deviations, respectively.

Hobbs and Baer ${ }^{(9)}$ used argon for the primary corresponding molecule, hexane for the shape correction corresponding molecule, and water for the polar corresponding molecule. Figure 2 shows a comparison between mea- 
sured shock Hugoniots ${ }^{(16)}$ and predicted shock Hugoniots using the JCZ3-EOS for $\mathrm{H}_{2} \mathrm{O}, \mathrm{C}_{6} \mathrm{H}_{14}, \mathrm{CCl}_{4}, \mathrm{CHCl}_{3}$, and $\mathrm{CH}_{2} \mathrm{Cl}_{2}$. The $\mathrm{H}_{2} \mathrm{O}$ Hugoniot, predicted with Eq. (3) with no polar corrections, lies above the data from Marsh ${ }^{(16)}$; and the $\mathrm{C}_{6} \mathrm{H}_{14}$ Hugoniot, predicted with Eq. (3) with no shape corrections, lies below the data. Corrections for polarity cause the predicted $\mathrm{H}_{2} \mathrm{O}$ Hugoniot to shift to lower pressures; whereas, shape corrections cause the predicted Hugoniot for $\mathrm{C}_{6} \mathrm{H}_{14}$ to shift to higher pressures. Figure 2.B shows Hugoniot predictions with molecules that are nonspherical. Chloroform $\left(\mathrm{CHCl}_{3}\right)$ and dichloromethane $\left(\mathrm{CH}_{2} \mathrm{Cl}_{2}\right)$ are also polar. McGee et al. ${ }^{(10)}$ found that the opposing shape and polar corrections where often nullified, as shown for $\mathrm{CH}_{2} \mathrm{Cl}_{2}$ in Fig. 2.B, for most of the polyatomic molecules with known critical property data. In this study, Eq. (3) was primarily used to determine force parameters for species with measured critical properties.

The corresponding states (CS) estimates of the EXP-13,6 force parameters using Eq. (3) give reasonable estimates of thermodynamic properties. For example, Fig. 3 shows JCZ3-EOS predictions of static properties of $\mathrm{N}_{2}$ using the CS estimation of $r^{*}$ and $\varepsilon / k$ of $4.0 \AA$ and $102 \mathrm{~K}$, respectively. The JCZ3-EOS gives accurate estimates of static volume, sound speed, and heat capacity to $10 \mathrm{Kbar}$, as shown with data ${ }^{(17)-(20)}$ in Fig. 3. A good test of the JCZ3-EOS is to compare calculated thermodynamic derivatives, such as the sound speed, $\sqrt{(d P / d \rho)_{s}}$, and heat capacity, $(d H / d T)_{p}$, to experimental data. Figure 3.B shows good agreement between calculated and measured sound speed. The measured constant pressure heat capacity should be used with caution, since the low-pressure $30 \mathrm{C}$ heat capacity measurements ${ }^{(20)}$ do not agree with well-known heat capacity data, as given in the JANNAF tables. ${ }^{(21)}$ The cubic behavior predicted by the JCZ3-EOS may be related to the transition of the Grüneisen function, which correctly describes limiting behavior at high and low densities. Even in this transition region, the JCZ3-EOS gives adequate agreement with the data.

Unfortunately, not all chemical species have critical properties. Critical properties of unstable species are rare and do not exist for free radical species. For heavy metals and many ionic compounds, reported values are typically calculated with questionable accuracy. About 150 of the 750 gas species listed in the JANNAF tables have both the critical temperature and critical volume. Of these 150 species, 93 also have LJ parameters. Thus, approximately 250 of the 750 JANNAF species can be obtained using either the corresponding states (CS) technique or can be estimated with known $\mathrm{LJ}$ constants.

\section{Molecular Volume Correlation}

The EXP-13,6 parameters for the remaining 500 gas species in the JANNAF tables were obtained by correlating the approach radius, as determined from the CS theory described in the preceding section, to molecular volume. Molecular volume was calculated by representing molecules as a collection of atoms with atomic radius equal to van der Waals radius. When atoms overlap in a molecule, the volume was only represented once. Atomic coordinates for all 750 JANNAF gas species were determined by Hobbs and Bear ${ }^{(22),(23)}$ and were used to calculate molecular volume. 
submitted to Propellants, Explosives, Pyrotechnics

Figure 4.A shows a strong correlation between the molecular volume calculated using van der Waals radii and the radius of the minimum pair potential energy, $r^{*}$, for 93 species calculated with critical volumes. Most of the species that deviate farthest from the linear correlation in Figure 4.A are monoatomic. The monoatomic species were eliminated from the least squares fit to obtain an improved correlation. The least squared linear correlation of the polyatomic species in Figure 4.A can be used to estimate r* from molecular volumes:

$$
r^{*}=1.19(\text { MolecularVolume })^{(1 / 3)}+0.68 .
$$

The corrected $\mathrm{LJ}$ characteristic diameters, $\sigma \times 2^{1 / 6}$, are also adequately correlated to molecular volume as shown in Figure 4.B. Again, most of the scatter in Figure 4.B is attributed to monoatomic or diatomic species. A similar correlation for $\varepsilon / k$ with molecular volume was unsuccessfully sought. Electron density calculated from the molecular volume did not correlate to the potential well depth determined with the CS theory or with the literature $\mathrm{LJ}$ values. An alternative method for determining $\varepsilon / k$ was developed. This method involves choosing $r^{*}$ based on Eq. (6) and determining $\varepsilon / k$ by matching high-pressure, pure species, isentropes calculated with the BKWS-EOS, which is described subsequently.

\subsection{BKW Databases}

The Becker-Kistiakowsky-Wilson equation of state (BKW-EOS) is used extensively to calculate detonation properties of condensed explosives:

$$
\frac{P V}{R T}=1+X e^{\beta X} \text { with } X=\frac{\kappa \sum n_{i} k_{i}}{V(T+\theta)^{\alpha}},
$$

where $P, V, R, T$, and $n_{i}$ represent pressure, molar gas volume, gas constant, absolute temperature, and mole fraction of the $i^{\text {th }}$ gaseous component, respectively. The summation extends over all components of the gaseous mixture. The covolume factors, $k_{i}$, represent excluded volume. The parameters $\alpha, \beta, \kappa$, and $\theta$ are empirical constants. Typically, the parameters $\alpha, \beta, \kappa, \theta$, and $\mathrm{k}_{\mathrm{i}}$ are adjusted to fit measured detonation properties.

Two different parameterizations of the BKW-EOS are in use: BKWC ${ }^{(24)}$ and BKWS ${ }^{(23)}$. The $\mathrm{C}$ and $\mathrm{S}$ represent $\underline{\mathrm{C} H E E T A H}{ }^{(3)}$ parameterization and $\underline{S}{ }^{2}{ }{ }^{(23)}$ parameterization, respectively. In the BKWS parameterization, only $\beta, \kappa, \theta$ were optimized to match detonation properties, and covolumes were based on physical arguments. In the BKWC parameterization, 31 parameters, including gas covolumes, $k_{i}$, were optimized to match detonation properties.

With the large number of adjustable parameters, the BKWC-EOS database was used to improve the prediction of detonation velocity and pressure over the BKWS by about $2 \%$ for energetic materials composed of $\mathrm{C}, \mathrm{H}, \mathrm{N}$, and $\mathrm{O}$. However, improvement in detonation property prediction is not justified when experimental variability (5$10 \%$ ) is considered. Also, the BKWC optimization was not constrained to consider measured properties, such as $\mathrm{H}$ and $\mathrm{O}$ van der Waal radii. The BKWC optimized covolume of $\mathrm{H}_{2}$ is larger than the covolume of $\mathrm{H}_{2} \mathrm{O}$, which is physically impossible. Significant errors are shown in pure liquid Hugoniot predictions using the BKWC-EOS in Section 5 . 
submitted to Propellants, Explosives, Pyrotechnics

The BKWC database is composed of only 23 gaseous products and 2 condensed products. However, the BKWS database is composed of 750 gaseous products and 400 condensed reaction products. The BKWS database is used in the present study to obtain the remaining $500 \varepsilon / k$ values, where critical properties or LJ data is unavailable.

\subsection{BKWS-EOS Estimates of $\varepsilon / k$}

Because the BKWS database provides acceptable results for high-pressure detonation states and the ideal gas law provides accurate results for low-pressure states, $\varepsilon / k$ can be estimated by matching isentropes at high-pressure and low-pressure states using the calculated $r^{*}$ from molecular volume data. In this study, the standard temperature and pressure $(298 \mathrm{~K}$ and $1 \mathrm{~atm})$ isentrope was chosen for fitting $\varepsilon / k$. Figure 5 shows the $298 \mathrm{~K}$ and $3,000 \mathrm{~K}$ isentrope for formyl fluoride. Parameters for the JCZS-EOS were chosen to be $r^{*}=4.50 \AA$, and $\varepsilon / k=150 \mathrm{~K}$, using Eq. (6) for $r^{*}$ and fitting $\varepsilon / k$ to match the high-pressure $298 \mathrm{~K}$ isentrope. Agreement between the JCZS and BKWS predictions at high-pressure for both isentropes indicates that fitting the $298 \mathrm{~K}$ isentrope is sufficient to match isentropes at significantly different conditions.

Not all values of $r^{*}$ predicted with Eq. (6) were adequate to match the BKWS isentropes. For such species, $r^{*}$ was slightly adjusted to match the BKWS isentrope. ${ }^{(10)}$ Equation (6) was used as an initial estimate of $r^{*}$, and both $r^{*}$ and $\varepsilon / k$ were fit to the BKWS isentrope. The force parameters for these "specially fit" molecules are not unique, and various combinations of parameters will give an adequate match to the BKWS isentrope.

Caution must be used when using the JCZS-EOS for molecules with $\varepsilon / k$ estimated from BKWS predictions. The parameters for these molecules are only as good as the BKWS predictions. Because the BKWS-EOS was calibrated at high-pressures with explosives composed primarily of $\mathrm{C}, \mathrm{H}, \mathrm{N}, \mathrm{O}, \mathrm{F}$, and $\mathrm{Cl}$, species with substantially different atomic compositions may be in error.

\subsection{Pure Liquid Shock Hugoniot Data}

One method to determine the accuracy of the BKWS and JCZS predictions would be to compare Hugoniot predictions to pure liquid shock Hugoniot data. Figure 6 shows a comparison between liquid shock Hugoniot data and predicted liquid shock Hugoniots, using the JCZS-EOS for water, hydrogen, carbon tetrachloride, trichloromethane, carbon dioxide, oxygen, argon, methanol, ammonia, and methane. The references for the data are given in Fig. 6. BKWS and BKWC predictions are shown for water and hydrogen in Figure 6.A and 6.B. The JCZS parameters are given in Table 1 along with the JCZS parameters for major species containing CHNO. The JCZS parameters can be used to adequately replicate liquid shock Hugoniot data. The BKWC predictions for the $\mathrm{H}_{2} \mathrm{O}$ and $\mathrm{H}_{2}$ Hugoniots are grossly inadequate.

Some caution must be used when using pure liquid shock Hugoniot data, since the species may break into smaller fragments at elevated temperatures and pressures. Sheffield ${ }^{(30)}$ suggests that if the Hugoniot deviates from the "universal" liquid Hugoniot, ${ }^{(31)}$ the species is likely breaking into smaller fragments. For example, Figure 7 shows the Hugoniot for liquid nitrogen with two predictions from the JCZS database by using $\mathrm{N}_{2}$ as the sole reaction product and by using both $\mathrm{N}$ and $\mathrm{N}_{2}$ as reaction products. The heat capacity for atomic $\mathrm{N}$ and $\mathrm{N}_{2}$ were taken from 
submitted to Propellants, Explosives, Pyrotechnics

Reference 32 and are thought to be good to $15,000 \mathrm{~K}$. At approximately $300 \mathrm{Kbars}$ and $7500 \mathrm{~K}$, the $\mathrm{N}_{2}$ breaks into $\mathrm{N}$. Fried and Howard ${ }^{(32)}$ used the hypernetted-mean spherical approximation with Monte Carlo simulations (HMSAMC) to calculate the Hugoniot for $\mathrm{N}_{2}$. The HMSA-MC pressure calculations were essentially identical to the JCZS predictions and are not shown in Figure 7. However, the HMSA-MC prediction of temperature along the Hugoniot is shown in Figure 7.B and are slightly different than the JCZS predictions. The differences in the temperature Hugoniot predictions may be due to slightly different heat capacity fits used in the simulations.

\subsection{DAKOTA Optimization}

The JCZS parameters, for the major species shown in Table 1, were slightly adjusted using constrained optimization to obtain optimal agreement with detonation velocity measurements. The sources of the initial $r^{*}$ values were either from the $\mathrm{LJ}$ values ( $\mathrm{lj}$ ), isentrope fit values (fit), or the corresponding states values (cs) and are labeled in the superscript of the $r^{*}$ 's in Table 1. During the fitting process, $r^{*}$ was found to be more sensitive than $\varepsilon / k$ when fitting BKWS isentropes. The $\varepsilon / k$ values were left as the original $l \mathrm{j}$, fit, or cs values.

CHEETAH, ${ }^{(3)}$ which is essentially a $\mathrm{C}$ version of the FORTRAN equilibrium code TIGER, ${ }^{(2)}$ was chosen as the analysis code to solve the CJ detonation problem for the 32 explosives used to parameterize the BKWC database. $^{(24)}$ An objective function was minimized using DAKOTA ${ }^{(35)}$ (Design Analysis Kit for OpTimizAtion). The objective function was the root mean square error $(r m s)$ between calculated $\left(D_{i, c}\right)$ and measured $\left(D_{i, c}\right)$ detonation velocities:

$$
r m s=\sqrt{\frac{1}{N} \sum_{i=1}^{N}\left(\frac{D_{i, m}-D_{i, c}}{D_{i, m}}\right)^{2}},
$$

where the subscripts $i, m$, and $c$ represent the $i^{\text {th }}$ explosive, measured, and calculated, respectively. $N$ represents the number of detonation velocity measurements, 32 .

Table 2 shows the overall percent RMS error for predicted detonation velocity and detonation pressure using the BKWS, BKWC, and two JCZS databases. The first JCZS database only considered the 44 species listed in Table 2 for the detonation calculations. The second JCZS predictions considered all 132 species in the JANNAF ${ }^{(21)}$ tables composed of species containing C, H, N, O, Cl, or F. Since the RMS percent errors for both JCZS databases are similar, the smaller JCZS data set is probably sufficient for energetic materials composed of $\mathrm{C}, \mathrm{H}, \mathrm{N}, \mathrm{O}, \mathrm{Cl}$, or $\mathrm{F}$.

Table 2 also shows the overall percent RMS error for predicted detonation velocities and detonation pressure of the explosives in Reference 24, excluding the nonideal explosives containing TATB (TATB, RX26, and LX17) and HNB. The nonideal explosives may not reach complete equilibrium and probably should not be considered in the RMS percent error calculation. Excluding nonideal explosives should make the RMS percent error smaller, as shown in Table 2 for the JCZS databases. However, the RMS percent error using the empirical BKWC database increases when nonideal explosives are excluded from the performance database. This unusual behavior of the BKWC database may be a result of the unconstrained optimization of the BKWC-EOS, as discussed in Section 4.1. 
submitted to Propellants, Explosives, Pyrotechnics

\subsection{Validation of the JCZS-EOS Database}

Detonation velocity measurements are probably good to within a few percent. ${ }^{(36)}$ Detonation pressure measurements are probably good to within $10-18 \% .{ }^{(37)}$ Similar to detonation pressure measurements, detonation temperature measurements are probably good to within $20 \%$. Detonation temperatures are measured by the brightness of the detonation front interacting with a detector. Void free systems, such as liquid explosives or single crystal systems, are believed to be more accurate. Measurements in porous systems include the effects of shocked air or perhaps low-density explosive material jetting into the voids rather than the brightness of the pure detonation products. Therefore, comparisons of measured detonation temperatures to calculated detonation temperatures should be done with caution.

In the present work, two explosive performance databases are used to evaluate the JCZS-EOS database: the LLNL performance database ${ }^{(24)}$ (as used in Table 2) and the SNL performance database. ${ }^{(23)}$ Explosives in the LLNL performance database consist of 32 detonation velocity measurements and 31 detonation pressure measurements. Since the LLNL database was used to optimize some of the $r^{*}$ values in Table 1, a different set of explosives is needed to validate the JCZS-EOS database. Explosives in the SNL performance database consist of 111 detonation velocities, 67 detonation pressures, and 14 detonation temperature measurements for explosives that contain $\mathrm{C}, \mathrm{H}, \mathrm{N}$, $\mathrm{O}, \mathrm{Cl}$, and $\mathrm{F}$ at various densities. The SNL performance database will be used to validate the prediction of detonation velocity, pressure, and temperature. The LLNL performance database will be used to examine total energy of detonation and expansion energies since these parameters were not considered in the optimization procedure.

Another method of evaluating the JCZS-EOS database is to compare measured detonation velocity of gases at high initial pressures to predictions. The detonation velocity of various gases at high initial pressures were measured by Bauer ${ }^{(38)}$ and evaluated by Schmitt. ${ }^{(39)}$

\subsection{Explosive Performance}

A comparison of JCZS predictions to measured detonation velocities and pressures are given in Figure 8 for the SNL performance database. Table 3 shows the overall percent RMS error in predicting detonation velocity, pressure, and temperature using the BKWS-EOS, BKWC-EOS, JCZS-small, and JCZS-large databases. Figure 9 shows predicted and measured detonation velocities for four common high explosives over a wide initial density range. The references for the data in Fig. 9 are given by Hobbs and Baer. ${ }^{(23)}$ The predicted pressure range is also given in Fig. 9 for HMX, RDX, PETN, and TNT, showing the range of pressures used in the detonation calculations. The better agreement with data using the JCZS-EOS database is consistent with the results from the LLNL performance database given in Table 2. The overall percent RMS error in the predicted detonation temperatures is higher for the JCZSEOS than the BKWC-EOS. However, the predicted RMS error is within the expected accuracy of the optical temperature measurements which may be as high as $20 \%$. The JCZS predicted detonation temperatures are similar to measured detonation temperatures for homogeneous explosives. For example, the RMS error for the NM detonation temperature is $0.3 \%$ for the JCZS-EOS compared to $6.8 \%$ for the BKWC-EOS. 
submitted to Propellants, Explosives, Pyrotechnics

\subsection{Expansion States}

Table 4 gives the percent RMS error for the total energy of detonation, which is labeled as E, and the expansion energies as relative volumes of $2.2,4.1$, and 6.5 , labeled as $E_{2.2}, E_{4.1}$, and $E_{6.5}$. The JCZS prediction of the total energy of detonation is the same as the BKWC predictions and better than the BKWS predictions. The expansion energies predicted with the JCZS-EOS were within $2 \%$ of the BKWC predictions, which were calibrated to match the experimental measurements. A better comparison of the expansion energy would be to compare cylinder wall velocities as predicted with a shock physics code.

\subsection{Gas Detonations at High Initial Pressures}

Figure 10 shows predicted (lines) and measured ${ }^{(38)}$ (symbols) detonation velocities of various gases at different elevated initial pressures The compositions of the gas mixtures are also shown in Figure 10. The BKWC database does not consider $\mathrm{H}$ and $\mathrm{OH}$ as reaction products and cannot adequately predict the detonation velocities for the hydrogen-oxygen system, as shown in Figure 10.A. The JCZS-EOS database adequately predicts the detonation velocity for all the gas mixtures in Figure 10.

\subsection{Prediction of Nonideal Explosives: AN and AP}

Nonideal explosives typically have small critical diameters, and when the charge diameter is smaller than the critical diameter, a steady-state detonation wave cannot be sustained. If the charge diameter is sufficiently large, the detonation wave should propagate at velocities predicted by the JCZS-EOS. Miyake et al ${ }^{(40)}$ measured the steady detonation velocity of AN in steel tubes with different diameters and wall thicknesses. The value of the detonation velocity and pressure for AN at an initial density of $0.85 \mathrm{~g} / \mathrm{cm}^{3}$ at the largest tube diameter of $30 \mathrm{~cm}$ was $3.95 \mathrm{~km} / \mathrm{s}$ and $34 \mathrm{Kbar}$, respectively. The JCZS-EOS prediction of the AN detonation velocity and pressure is $3.93 \mathrm{~km} / \mathrm{s}$, and 35

Kbar. The infinite diameter detonation velocity of ammonium perchlorate (AP) at an initial density of $1.0 \mathrm{~g} / \mathrm{cm}^{3}$ was determined by Price et al. ${ }^{(41)}$ to be $3.70 \mathrm{~km} / \mathrm{s}$. The JCZS-EOS predicted detonation velocity of AP is $3.73 \mathrm{~km} / \mathrm{s}$. Although the agreement between predicted and measured detonation velocities for AN and AP are reasonable, the reader should be cautious when using the JCZS-EOS for energetic materials that behave nonideally. Partial or complete physical separation of oxidizers and fuel particles may result in diffusion or kinetic limitations in which the equilibrium assumption is not valid. Partial equilibrium calculations, such as those used by Howard et al., ${ }^{(42)}$ force agreement with data by arbitrarily allowing part of the oxidizer or fuel to react. Differences between measurements and calculations may result from an inadequate gas-phase EOS, condensed-phase EOS, kinetically controlled reactions, etc. The JCZS-EOS should give better predictions of gas behavior and aid in separating EOS effects from kinetic effects in nonideal explosives.

\subsection{Summary and Conclusions}

The EXP- $\eta, 6$ potential used in the JCZ3-EOS was shown in this study to be least sensitive to changes in $\eta$ and most sensitive to changes in $r^{*}$ and $\varepsilon / k$. Thus, $\eta$ was assumed to be 13 for all molecules, and $r^{*}$ and $\varepsilon / k$ were 
submitted to Propellants, Explosives, Pyrotechnics

determined for 750 gas molecules. The force constants for this library, $r^{*}$ and $\varepsilon / k$, have been obtained by using pure liquid shock Hugoniot data; by correcting the $\mathrm{LJ}$ characteristic approach radii $(\sigma)$ to conform to the mathematical form of the EXP-13,6 potential function and using literature values for the potential well depth; by using corresponding states theory to calculate the EXP-13,6 force constants; and by using a semi-empirical formula based on molecular volume to determine the approach radii and obtaining the potential well depth by matching isentropes with the BKWS-EOS. Some of the EXP-13,6 parameters were slightly adjusted to predict optimal detonation velocities using the optimization toolkit DAKOTA.

The validity of the corresponding states method of obtaining force constants was examined by predicting static properties of $\mathrm{N}_{2}$. The JCZ3-EOS gives accurate estimates of static volume, sound speed, and heat capacity up to $10 \mathrm{Kbar}$ using EXP-13,6 parameters obtained from corresponding states estimates. A four-parameter corresponding states approximation to account for shape and polarity corrections was also investigated. Pure liquid Hugoniot calculations of $\mathrm{H}_{2} \mathrm{O}, \mathrm{C}_{6} \mathrm{H}_{14}, \mathrm{CCl}_{4}, \mathrm{CHCl}_{3}$, and $\mathrm{CH}_{2} \mathrm{Cl}_{2}$ were in good agreement with data. Additional JCZ3-EOS predictions of pure liquid shock Hugoniots for $\mathrm{H}_{2}, \mathrm{CO}_{2}, \mathrm{O}_{2}, \mathrm{Ar}, \mathrm{CHOOH}, \mathrm{NH}_{3}, \mathrm{CH}_{4}$, and $\mathrm{N}_{2}$ were in good agreement with data.

Detonation simulations have been performed with the JCZS-EOS database and have displayed excellent agreement with experimental results for detonation velocity, detonation pressure, and detonation temperature. Predicted detonation velocities, with the JCZS-EOS, are shown to be within $2 \%$ of measured values for many explosives. The predicted velocities with the BKWC-EOS for the same set of explosives was shown to be within 3\%. The detonation pressure, temperature, and expansion states were all shown to be within $10 \%$ of reported values. The JCZSEOS is shown to predict low-density explosives with the same accuracy as high-density explosives. The JCZS-EOS predictions of explosive performance of AN and AP were in good agreement with experimental results.

The JCZ3-EOS with the improved product species database has been shown to adequately predict detonation states, as well as expansion states, for various explosives. Better agreement between measured detonation performance and predicted detonation performance for gases at elevated initial pressures is attributed to a larger product species database with an adequate physical description of molecular interactions. Such predictions support the hypothesis that improved predictions of explosive performance can be realized by using a more fundamental EOS with an adequate number of product species, rather than merely increasing the number of fitting parameters used by empirical based equations of states.

\subsection{References}

(1) Cowperthwaite, M. and Zwisler, W. K., "The JCZ Equations of State for Detonation Products and Their Incorporation into the TIGER Code," Sixth Symposium (International) on Detonation, ACR-221, Office of Naval Research, Arlington, VA, 162 (1976).

(2) Cowperthwaite, M., and Zwisler, W. H., TIGER Computer Program Documentation, PYU-1182, PYU-2559, PYU-1397, Stanford Research Institute, Menlo Park, CA (1973).

(3) Fried, L. E., Cheetah 1.39 User's Manual, UCRL-MA-117541 Rev. 3, Lawrence Livermore National Laboratory, Livermore, California (1996). 
(4) Kerley, G. I., "Theoretical Equations of State for the Detonation Products of Explosives," Eighth Symposium (International) on Detonation, NSWC MP 86-194, 540 (1985). See also "User's Manual for PANDA: A Computer Code for Calculating Equations of State," Los Alamos National Laboratory, LA-8833-M (1981).

(5) Nichols, A. L. III and Ree, F. H., CHEQ 2.0 User's Manual, UCRL-MA-106754, Lawrence Livermore National Laboratory, Livermore, California (1990).

(6) Fickett, W. and Davis, W. C., Detonation, University of California Press, Berkeley, CA (1979).

(7) Baker, E. L. and Stiel, L. I., "Optimized JCZ3 Procedures for the Detonation Properties of Explosives," Eleventh International Detonation Symposium, Office of Naval Research, Arlington, VA (1998).

(8) Jacobs, S. J., "On the Equation of State of Compressed Liquids and Solids," NOLTR 68-214, United States Naval Ordnance Laboratory, White Oak, MD (1968).

(9) Hobbs, M. L. and Baer, M. R., "Predictions of Pure Liquid Shock Hugoniots," Twenty-Fourth International Pyrotechnics Seminar, Monterey California, 301 (1998).

(10) McGee, B. C., Hobbs, M. L., and Baer, M. R. "Exponential 6 Parameterization for the JCZ3-EOS," Sandia National Laboratories Report No. SAND98-1191 (1998).

(11) Hirschfelder, J. O., Curtiss, C. F., and Bird, R. B., Molecular Theory of Gases and Liquids, Wiley, New York, 234 (1954).

(12) van der Waals, J. D. Sr., Doctoral Dissertation, Leiden (1873).

(13) Pitzer, K. S., “Corresponding States for Perfect Liquids," J. of Chem. Phys., 7, 583 (1939).

(14) Ross, M. and Ree, F. H., "Repulsive forces of simple molecules and mixtures at high density and temperature," J. Chem. Phys., 73(12), 6146 (1980).

(15) Wilding, W. V., and Rowley, R. L., "A Four-Parameter Corresponding States Method for the Prediction of Thermodynamic Properties of Polar and Nonpolar Fluids," Int. J. of Thermophysics, 7(3), 525 (1986).

(16) Marsh, S. P., editor, LASL Shock Hugoniot Data, University of California Press, Berkeley, CA (1980).

(17) Kortbeek, P. J., Trappeniers, N. J., and Biswas, S. N., "Compressibility and Sound Velocity Measurements on $\mathrm{N}_{2}$ up to $1 \mathrm{GPa}$," International Journal of Thermophysics, 9 (1), 103 (1988).

(18) Robertson, S. L., and Babb, S. E., Jr., "Isotherms of Nitrogen to $400 \mathrm{C}$ and 10,000 Bar," The Journal of Chemical Physics, 50 (10), 4560 (1969).

(19) Malbrunot, P. and Vodar, B., "Experimental $p V T$ Data and Thermodynamic Properties of Nitrogen up to $1000 \mathrm{C}$ and 5000 Bar," Physica, 66, 351 (1973).

(20) Perkins, R. A., Roder, H. M., and Friend, D. G., "The Thermal Conductivity and Heat Capacity of Fluid Nitrogen," Physica A, 173, 332 (1991).

(21) Chase, M. W. Jr., Davies, C. A., Downey, J. R., Jr., Frurip, D. J., McDonald, R. A., Syverud, A. N., JANNAF Thermochemical Tables, Third Edition, J. of Phys. and Chem. Ref. Data, 14, Supplement No. 1 (1985).

(22) Hobbs, M. L. and Baer, M. R., "Nonideal Thermoequilibrium Calculations Using a Large Product Species Data Base," SAND92-0482, UC-741, Sandia National Laboratories, Albuquerque, NM (1992).

(23) Hobbs, M. L. and Baer, M. R., "Calibrating the BKW-EOS with a Large Product Species Database and Measured C-J Properties," Tenth International Detonation Symposium, ONR 33395-12, Office of Naval Research, Arlington VA, 409 (1993).

(24) Fried, L. E., and Souers, P. C., "BKWC: An Empirical BKW Parameterization Based on Cylinder Test Data," Propellants, Explosives, Pyrotechnics, 21, 215 (1996). 
submitted to Propellants, Explosives, Pyrotechnics

(25) Zubarev, V. N., and Telegin, "The Impact Compressibility of Liquid Nitrogen and Solid Carbon Dioxide," Sov. Physi.. Dokl., 7, 34 (1962). Data from this paper reduced by Ross and Ree. ${ }^{(14)}$

(26) Nellis, W. J., and Mitchell, A. C., "Shock compression of liquid argon, nitrogen, and oxygen to $90 \mathrm{GPa}(900$ kbar)," J. Chem. Phys., 73, 6137 (1980).

(27) van Thiel, M. and Alder, B. J., "Shock Compression of Argon," J. Chem. Phys., 44 (3), 1056 (1966).

(28) Kovel, M. I., "The Shock Wave Hugoniot and Electrical Conductivity of Liquid Ammonia in the Pressure Range $45 \mathrm{~kb}$ to $282 \mathrm{~kb}$," $\mathrm{Ph}$ :D. Thesis, Lawrence Livermore Laboratory, UCRL-51367, University of California, Livermore, CA (1973).

(29) Nellis, W. J., Ree, F. H., van Thiel, M., Mitchell, A. C., "Shock Compression of Liquid Carbon Monoxide and Methane to $90 \mathrm{GPa}$ (900 kbar)," J. Chem. Phys., 75 (6), 3055 (1981).

(30) Sheffield, S. A., private communication at Sandia National Laboratories (1996).

(31) Woolfolk, R. W., Cowperthwaite, M., and Shaw, R., "A 'Universal' Hugoniot for Liquids," Thermochemica Acta, 5, 409 (1973).

(32) Fried, L. E., and Howard, W. M., "An Accurate Equation of State for the Exponential-6 Fluid Applied to Dense Supercritical Nitrogen," J. of Chem. Phys., submitted for publication (1998).

(33) Nellis, W. J., Radousky, H. B., Hamilton, D. C., Mitchell, A. C., Holmes, N. C., Christianson, K. B., and van Thiel M., "Equation-of-state, shock-temperature, and electrical-conductivity data of dense fluid nitrogen in the region of the dissociative phase transition,", J. Chem. Phys., 94, 2244 (1991).

(34) Voskoboinikov, I. M., Gogulya, M. F., and Dolgoborodov, "Temperatures of shock compression of liquid nitrogen and argon," Sov. Physi. Dokl., 24, 375 (1979).

(35) Eldred, M. S., "Optimization Strategies for Complex Engineering Applications," SAND98-0340, UCC-705, Sandia National Laboratories, Albuquerque, NM (1998).

(36) Mader, C. L., Numerical Modeling of Detonations, University of California Press, Los Angeles, CA (1979).

(37) Davis, W. C., and Venable, D., "Pressure Measurements for Composition B-3,"Fifth Symposium (International) on Detonation, ACR-184, 13 (1970).

(38) Bauer, P. A., "Contribution of L'Etude De La Detonation De Melanges Explosifs Gazeux A Pression Initiale Elevvee," Ph. D. Thesis L'Universite De Pointiers (1985).

(39) Schmitt, R. G., "Analysis of Gas-phase Detonation Wave Structure at Elevated Initial Pressures," Ph. D Thesis, The University of Iowa (1994). See also, Schmitt, R. G., and Butler, P. B., "Detonation Properties of Gases at Elevated Initial Pressures," Combust. Sci. and Tech., 106, 167 (1995).

(40) Miyake, A., van der Steen, A. C., and Kodde, H. H., "Detonation Velocity and Pressure of the Non-ideal Explosive Ammonium Nitrate," Ninth Symposium (International) on Detonation, OCNR 113291-7, Office of Naval Research, Arlington VA, 560 (1989).

(41) Price, D., Clairmont, A. K., Erkman, J. O., and Edwards, D. J., "Infinite Diameter Detonation Velocities of Ammonium Perchlorate," Combustion and Flame, 13, 104 (1968).

(42) Howard, W. M., Fried, L. E., and Souers, P. C., "Kinetic Modeling of Non-Ideal Explosives with Cheetah," Eleventh International Detonation Symposium, Snowmass, CO (1998).

\section{Acknowledgments}

We wish to thank Art Ratzel for providing the opportunity and funding for this project. Mike Eldred helped set up the DAKOTA optimizer used to refine the $r^{*}$ values for major CHNOCIF species. The feedback from internal reviewers at Sandia National Laboratories (Bob Schmitt, Stewart Silling, and Sheldon Tieszen) is appreciated. 


\section{Tables}

Table 1. Subset of parameters used in JCZS database ${ }^{a}$

\begin{tabular}{|c|c|c|c|c|c|}
\hline ras & $r^{*}$ & s/k & Gas & $r^{2}$ & $8 h$ \\
\hline $\mathrm{CClF}_{3}$ & $4.71^{1 j}$ & 244 & Co & $3.88^{\mathrm{jj}}$ & 98 \\
\hline CCIFO & $5.06^{\mathrm{fit}}$ & 300 & $\mathrm{CO}_{2}$ & $4.22^{1 \mathrm{j}}$ & 244 \\
\hline $\mathrm{CCl}_{4}$ & $5.98^{\mathrm{es}}$ & 631 & $\mathbf{C}_{2} \mathbf{F}_{3} \mathbf{N}$ & $5.86^{\mathrm{cs}}$ & 252 \\
\hline $\mathrm{CF}_{2}$ & $4.87^{j j}$ & 94.2 & $\mathrm{C}_{2} \mathbf{F}_{4}$ & $6.03^{\mathrm{cs}}$ & 2.48 \\
\hline $\mathrm{CF}_{2} \mathrm{O}$ & $5.59^{\mathrm{cs}}$ & 240 & $C_{2} F_{6}$ & $7.36^{\mathrm{cs}}$ & 237 \\
\hline $\mathrm{CF}_{3}$ & $5.65^{1 \mathrm{j}}$ & 121 & $\mathrm{C}_{2} \mathrm{H}_{4}$ & $4.50^{1 \mathrm{j}}$ & 281 \\
\hline $\mathrm{CF}_{4}$ & $6.40^{\mathrm{lj}}$ & 134 & $\mathrm{C}_{2} \mathrm{H}_{6}$ & $4.01^{\mathrm{lj}}$ & 252 \\
\hline $\mathrm{CF}_{4} \mathrm{O}$ & $6.40^{\text {fit }}$ & 200 & $\mathrm{C}_{3} \mathrm{O}_{2}$ & $5.22^{\mathrm{cs}}$ & 361 \\
\hline CFO & $4.72^{\mathrm{fit}}$ & 200 & $\mathrm{ClH}$ & $3.35^{\mathrm{cs}}$ & 263 \\
\hline $\mathrm{CHCl}_{3}$ & $6.05^{\mathrm{lj}}$ & 340 & FH & $3.70^{\mathrm{j}}$ & 330 \\
\hline $\mathrm{CH}_{2} \mathrm{ClF}$ & $4.86^{\mathrm{jj}}$ & 318 & $\mathbf{H}$ & $2.00^{\mathrm{j} j}$ & 145 \\
\hline $\mathrm{CH}_{2} \mathrm{~F}_{2}$ & $4.36^{\mathrm{jj}}$ & 318 & $\mathbf{H}_{2}$ & $2.85^{\mathrm{jj}}$ & 38 \\
\hline $\mathrm{CH}_{2} \mathrm{O}$ & $4.40^{\mathrm{cs}}$ & 330 & $\mathrm{H}_{2} \mathrm{O}$ & $3.06^{1 \mathrm{j}}$ & 356 \\
\hline $\mathrm{CH}_{2} \mathrm{O}_{2}$ & $4.46^{\mathrm{fit}}$ & 200 & $\mathbf{H}_{3} \mathbf{N}$ & $3.33^{\mathrm{ji}}$ & 481 \\
\hline $\mathrm{CH}_{3}$ & $4.15^{\mathrm{jj}}$ & 144 & HO & 3.29 j & 80 \\
\hline $\mathbf{C H}_{3} \mathbf{F}$ & $4.95^{c s}$ & 256 & $\mathbf{N}$ & $2.25^{\mathrm{ft}}$ & 71 \\
\hline $\mathrm{CH}_{3} \mathrm{OH}$ & $4.23^{\mathrm{lj}}$ & 482 & $\mathbf{N}_{2}$ & $4.00^{\mathrm{cs}}$ & 102 \\
\hline $\mathrm{CH}_{4}$ & $4.23^{\mathrm{cs}}$ & 154 & $\mathrm{~N}_{2} \mathrm{O}$ & $5.18^{\mathrm{j}}$ & 232 \\
\hline $\mathrm{CHF}_{3}$ & $5.71^{\mathrm{es}}$ & 242 & No & $4.15^{\mathrm{jj}}$ & 117 \\
\hline CHFO & $4.50^{\mathrm{fit}}$ & 150 & $\mathrm{NO}_{2}$ & $4.77^{\mathrm{cs}}$ & 349 \\
\hline CHNO & $4.80^{\mathrm{j}}$ & 232 & $\mathrm{O}_{2}$ & $3.86^{\mathrm{cs}}$ & 125 \\
\hline CNO & $4.89^{\mathrm{jj}}$ & 232 & Ar & $3.85^{\mathrm{cs}}$ & 122 \\
\hline
\end{tabular}

(a) The superscripts $l j, c s$, and fit refer to the Lennard Jones, corresponding states, and $B K W$ fitting methods. The methods used to obtain the force constants are discussed in detail in the text.
Table 2. RMS percent errors - optimization

\begin{tabular}{|c|c|c|c|c|}
\hline EOS - \# of gases & $\mathbf{D}^{\mathrm{a}}, \%$ & $\mathrm{D}^{\mathrm{b}}, \%$ & $\mathrm{P}^{\mathrm{a}} \%$ & $\mathrm{P}_{\text {b }} \%$ \\
\hline BKWS - 132 & 5.1 & 5.2 & 9.5 & 9.5 \\
\hline BKWC-22 & 2.3 & $\mathbf{2 . 5}$ & 8.2 & $\mathbf{8 . 2}$ \\
\hline JCZS - 44 & 2.6 & $\mathbf{2 . 1}$ & 8.5 & $\mathbf{8 . 1}$ \\
\hline JCZS - 132 & 2.6 & 2.2 & 8.3 & 8.0 \\
\hline
\end{tabular}

(a) All explosives in Ref. 24 (includes nonideal explosives).

(b)All explosives in Reference 24 excluding the nonideal explosives containing TATB and HNB.

Table 3. RMS percent errors - validation

\begin{tabular}{|c|c|c|c|c|c|}
\hline EOS-gases & $\mathbf{D}^{\mathrm{a}} \%$ & $\mathbf{D}^{\mathrm{b}} \%$ & $\mathrm{P}^{\mathrm{a}} \%$ & $\mathbf{P}^{\mathrm{b}} \%$ & $\mathbf{T}^{\mathrm{a}} \%$ \\
\hline BKWS-132 & 5.1 & 5.1 & 10.5 & 10.5 & 4.2 \\
\hline BKWC-22 & 3.0 & $\mathbf{3 . 1}$ & 7.6 & $\mathbf{7 . 6}$ & $\mathbf{4 . 6}$ \\
\hline JCZS-44 & 2.3 & $\mathbf{2 . 0}$ & 8.3 & $\mathbf{8 . 2}$ & $\mathbf{9 . 0}$ \\
\hline JCZS-132 & 2.3 & 2.0 & 8.2 & $\mathbf{8 . 1}$ & $\mathbf{8 . 7}$ \\
\hline
\end{tabular}

(a) CHNOCLF explosives in Ref. 23 (includes nonideal explosives).

(b) CHNOCLF explosives in Ref. 23 excluding the nonideal explosives containing TATB and HNB.

Table 4. RMS percent errors - validation ${ }^{\mathrm{a}}$

\begin{tabular}{|c|c|c|c|c|}
\hline Database & $\mathrm{E}_{.} \%$ & $\mathrm{E}_{2.2}, \%$ & $\mathrm{E}_{4.1}, \%$ & $\mathrm{E}_{6.5} \%$ \\
\hline BKWS & 8.0 & 10.8 & 9.1 & 7.4 \\
\hline BKWC & 6.5 & 5.8 & 5.2 & 4.9 \\
\hline JCZS & 6.5 & 8.0 & 6.9 & 7.0 \\
\hline
\end{tabular}

(a) All explosives in Reference 24 excluding the nonideal explosives containing TATB and HNB. 


\section{Figure Captions}

1) Sensitivity of the potential function to $\eta$ and $\varepsilon / k$.

2) Pure liquid shock Hugoniots for A) $\mathrm{H}_{2} \mathrm{O}, \mathrm{C}_{6} \mathrm{H}_{14}$ and B) $\mathrm{CCl}_{4}, \mathrm{CHCl}_{3}, \mathrm{CH}_{2} \mathrm{Cl}_{2}$. The predictions (lines) were made using the JCZ3-EOS with potential parameters determined either from Eq. (3) or Eqs. (4) and (5). References for the data (symbols) are given in the legends.

3) Predicted (lines) and measured (symbols) static properties of $\mathrm{N}_{2}:$ A) PV isotherms, B) sound speed, and C) constant pressure heat capacity.

4) Correlation between molecular volume and A) $r^{*}{ }_{c s}$ for 95 species and B) $\sigma \times 2^{1 / 6}$ for 195 species. The linear correlation in $A$ is replotted in $B$ and labeled as Eq. (6).

5) 298-K and 3000-K formyl fluoride (CHFO) isentrope predictions using the ideal gas EOS, BKWS-EOS, and the JCZS-EOS.

6) Predicted (lines) and measured (symbols) Hugoniots for various species. The predictions in $\mathrm{C}$ and $\mathrm{D}$ were made with the JCZS database. Sources for the data are given in the legend.

7) Comparison of measured (symbols) and predicted (lines) A) pressure and B) temperature along the liquid nitrogen Hugoniot. Source of data is given in the legend.

8) Comparison between predicted and experimental detonation A) velocities and B) pressures. Source of the data is given in Ref. (23).

9) Comparison between predicted (lines) and measured (symbols) detonation velocities for A) HMX, B) RDX, C) PETN, and D) TNT. The predicted pressure range is given in each figure.

10) Predicted (lines) and measured ${ }^{(38)}$ (symbols) detonation velocities of gas mixtures at elevated initial pressures. 
Fig. 1

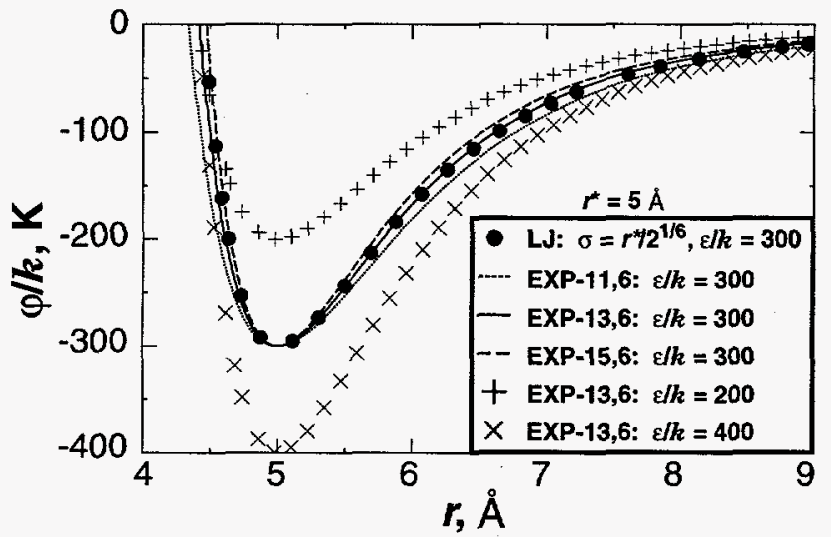


Fig. 2
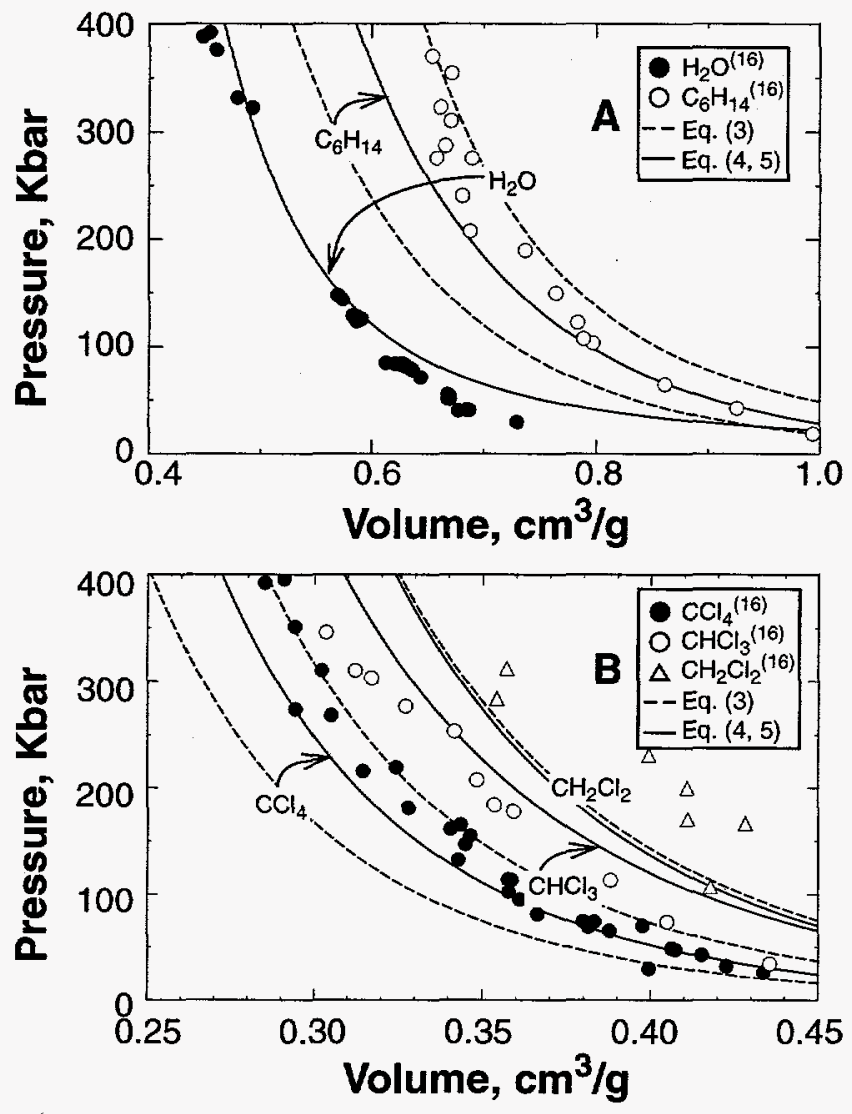
Fig. 3
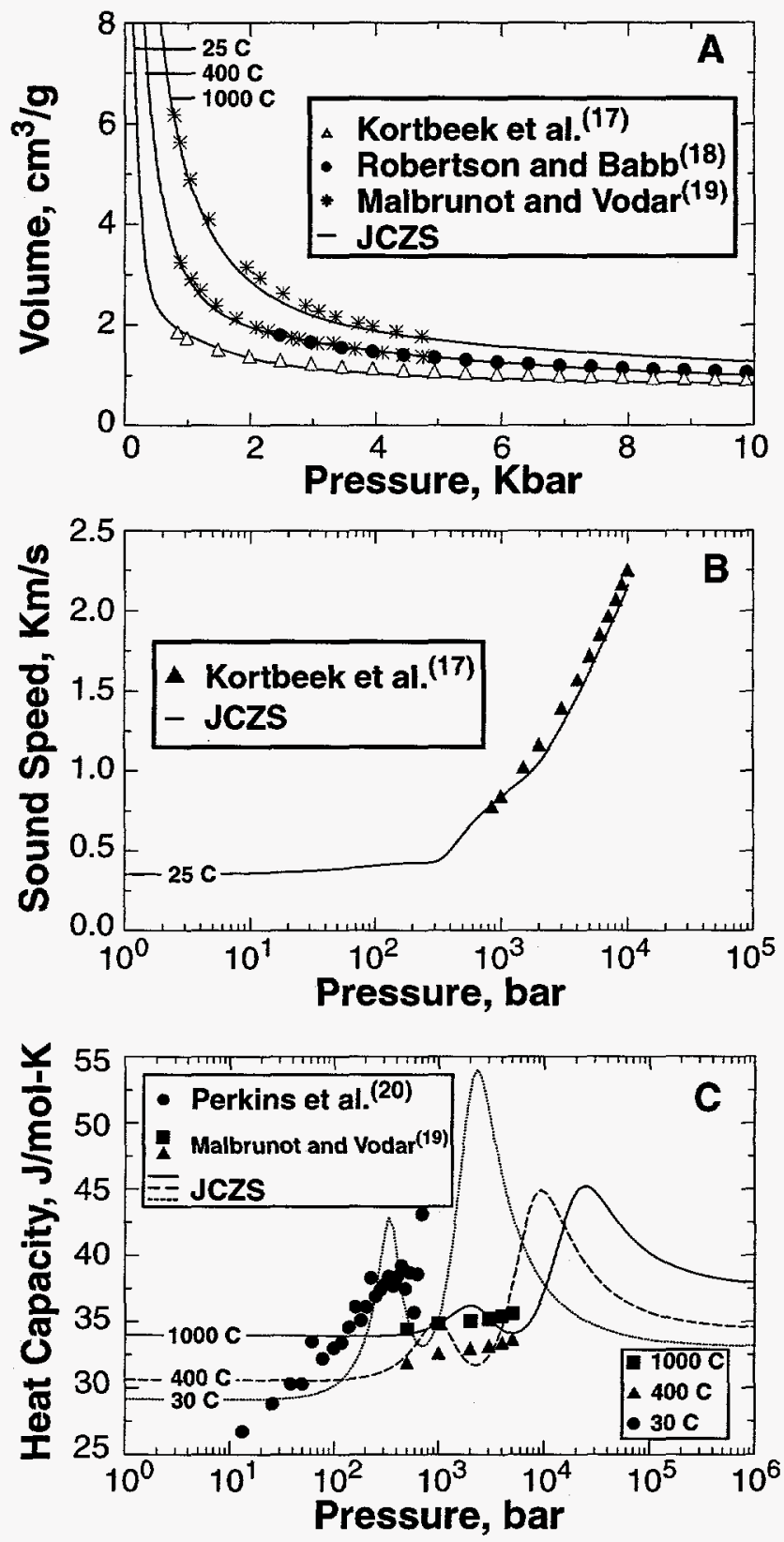
Fig. 4

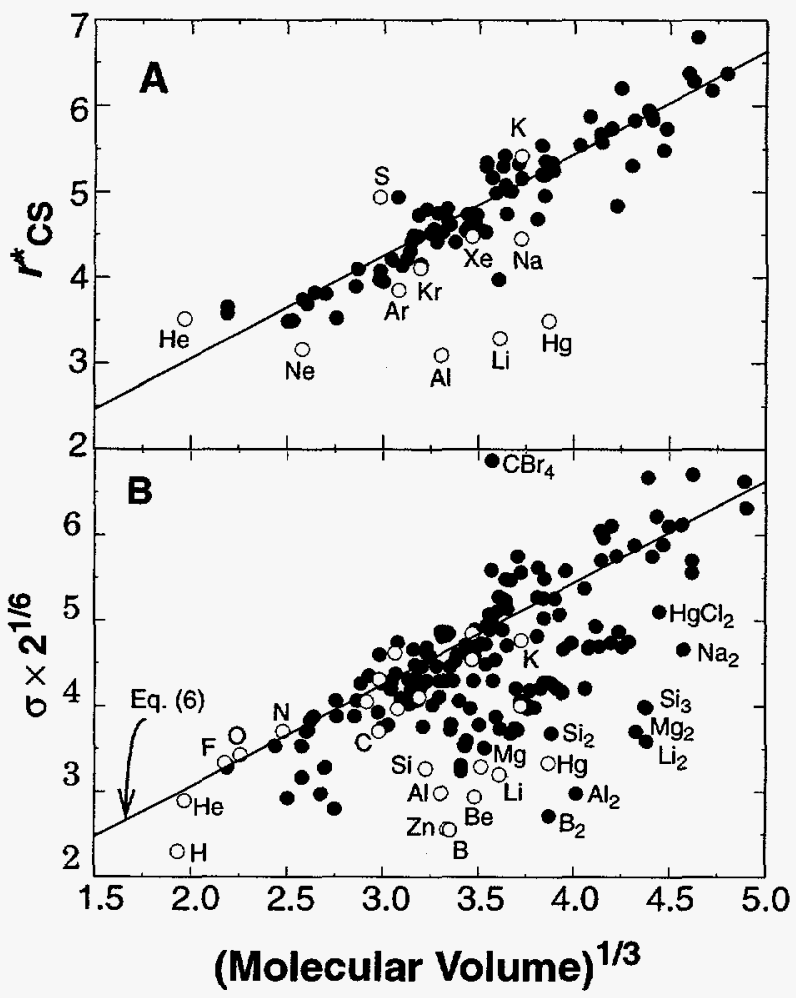


Fig. 5

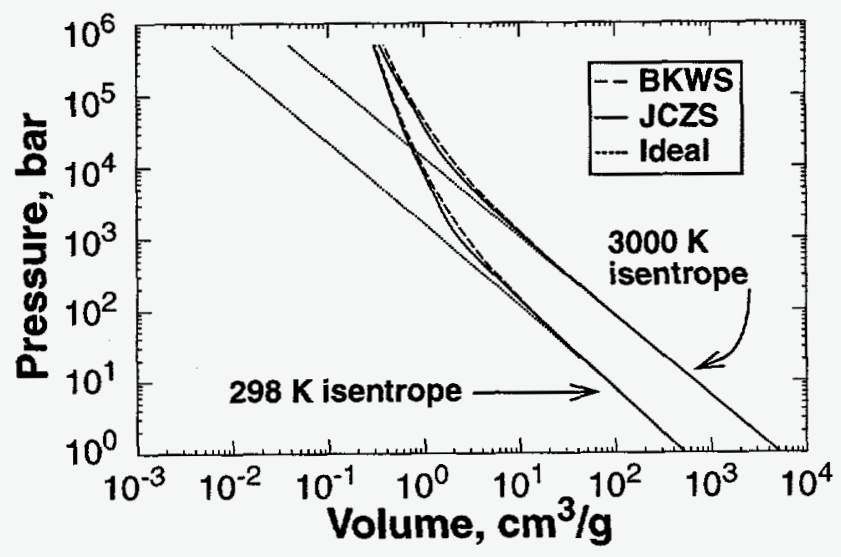


Fig. 6
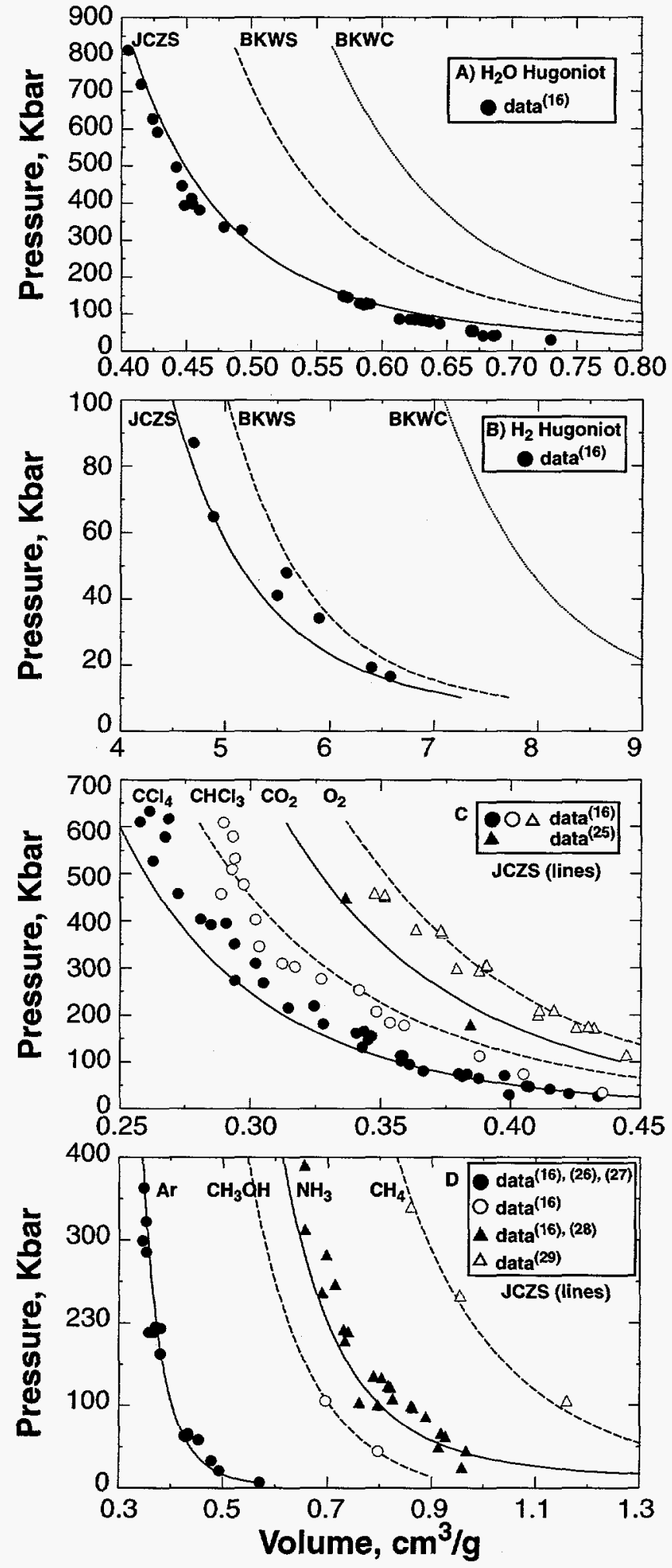
Fig. 7
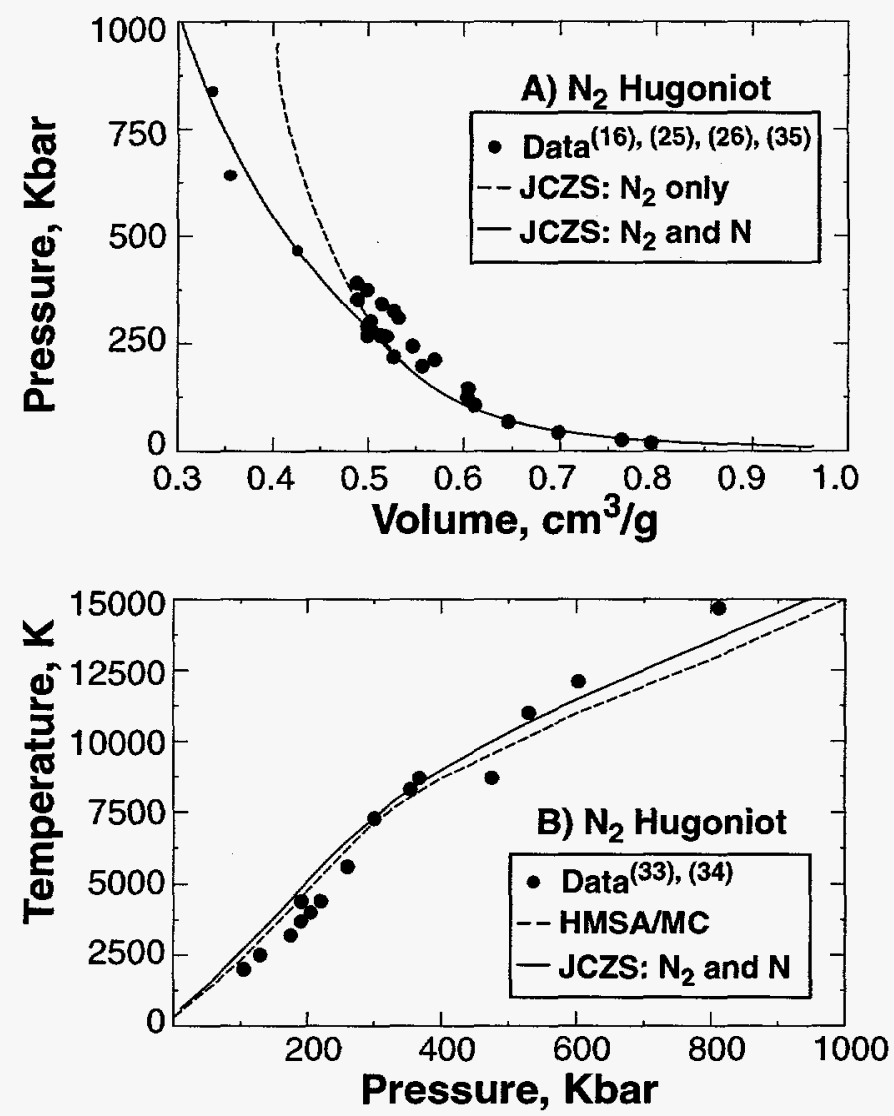
Fig. 8
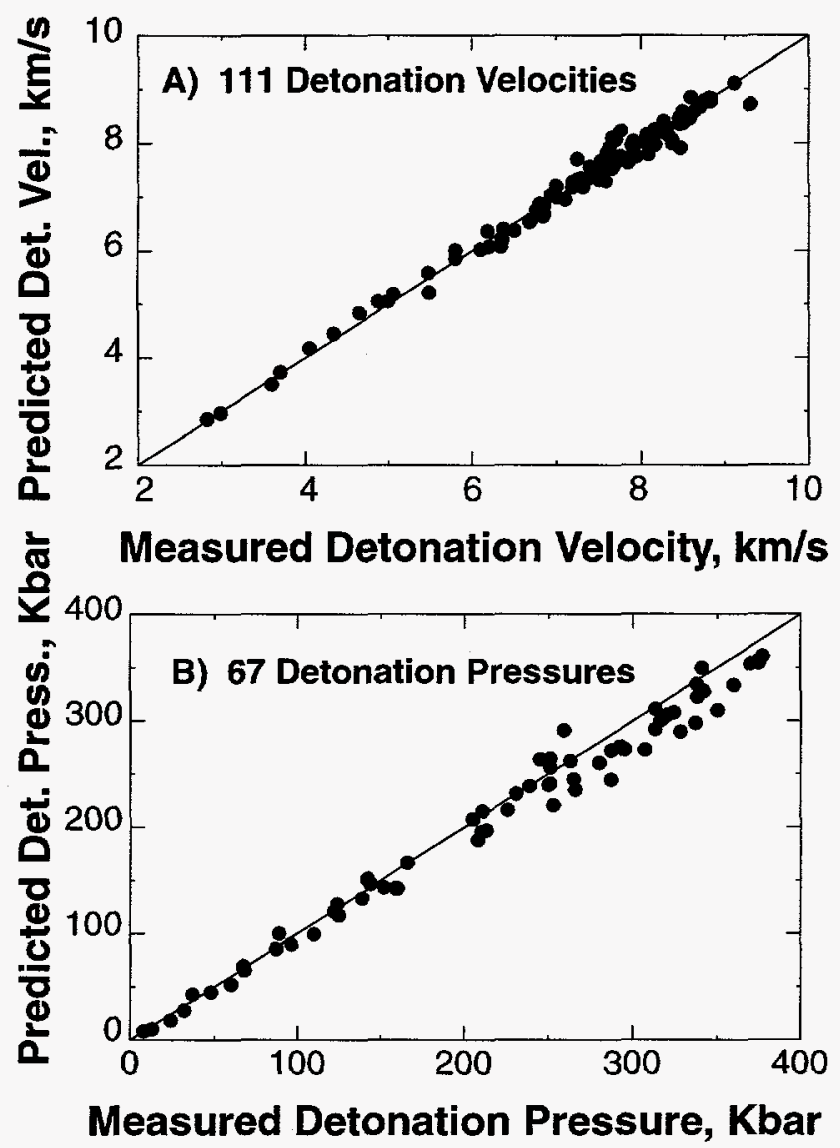
Fig. 9
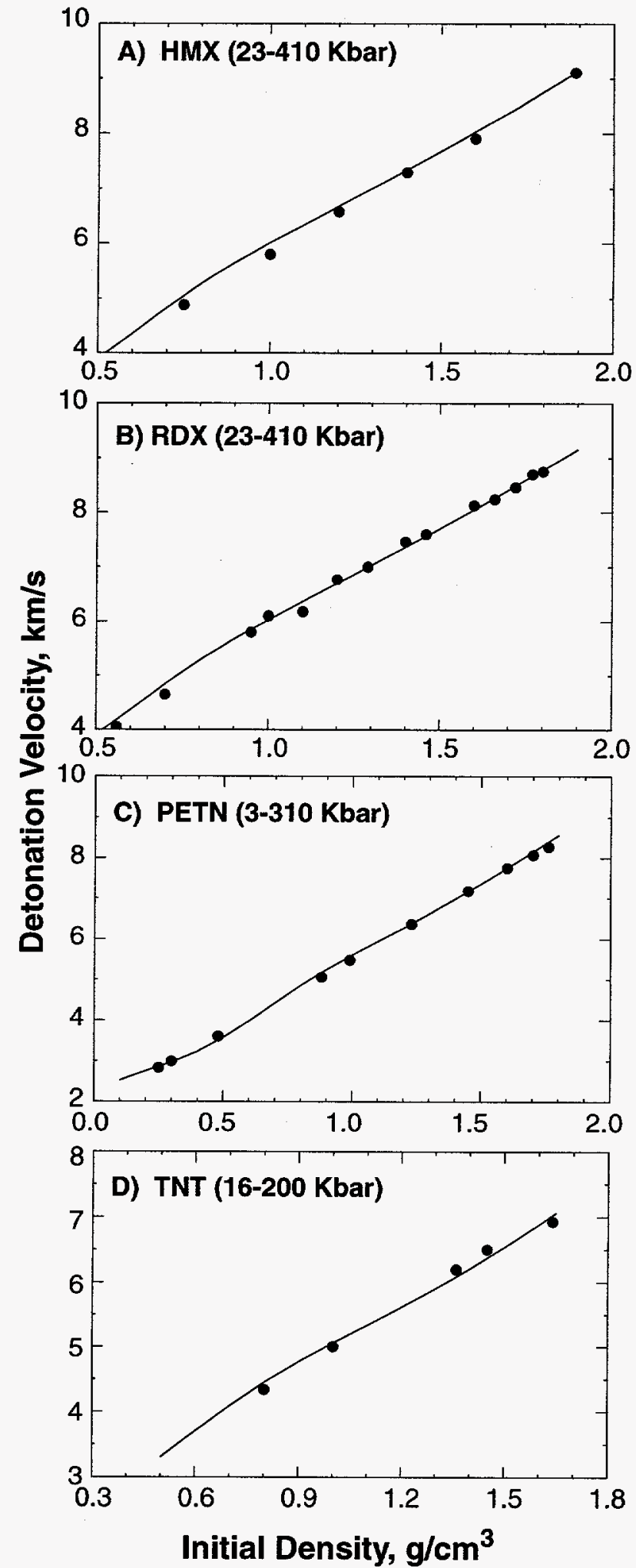


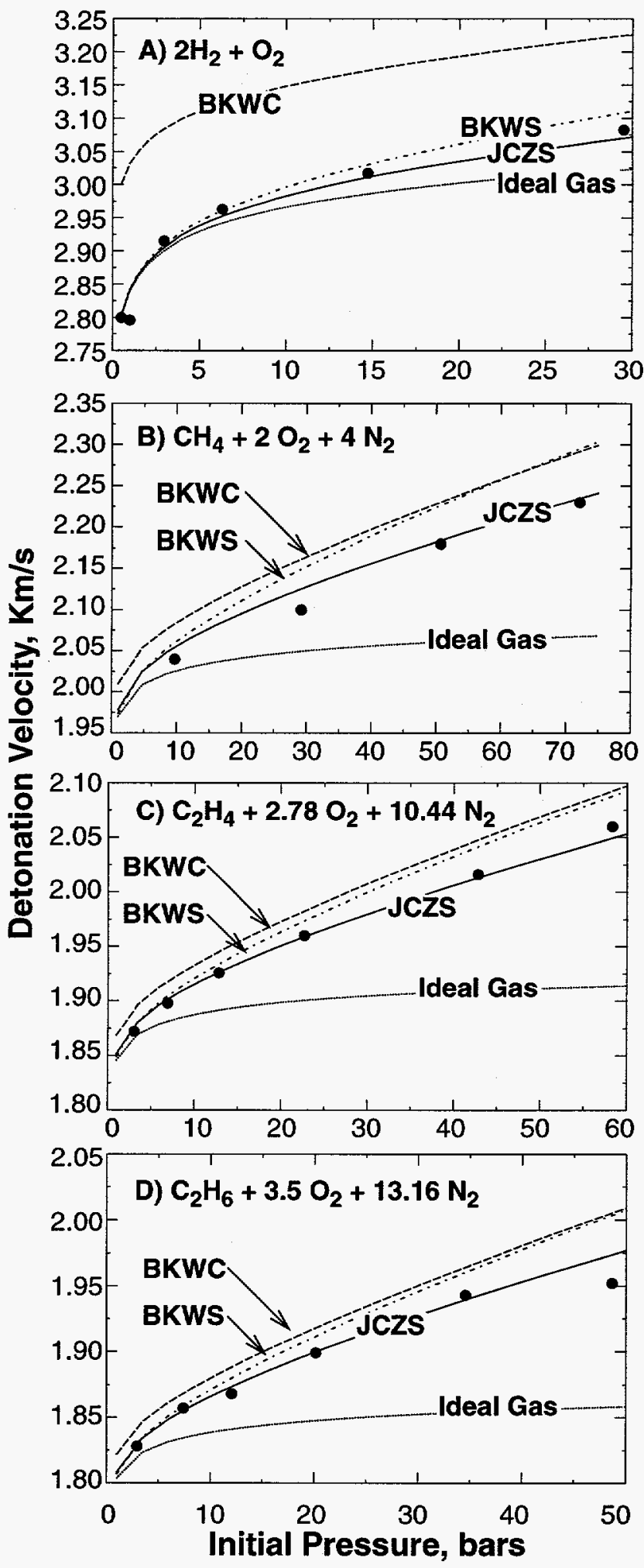

